University of Nebraska - Lincoln

DigitalCommons@University of Nebraska - Lincoln

Improvements in Channel Catfish Growth after Two Generations of Selection and Comparison of Performance Traits among Channel Catfish, Blue Catfish, and Hybrid Catfish Fingerlings in an Aquarium Rack System

Brian C. Small

United States Department of Agriculture, bsmall@ars.usda.gov

Follow this and additional works at: https://digitalcommons.unl.edu/usdaarsfacpub

Part of the Agricultural Science Commons

Small, Brian C., "Improvements in Channel Catfish Growth after Two Generations of Selection and Comparison of Performance Traits among Channel Catfish, Blue Catfish, and Hybrid Catfish Fingerlings in an Aquarium Rack System" (2006). Publications from USDA-ARS / UNL Faculty. 595.

https://digitalcommons.unl.edu/usdaarsfacpub/595

This Article is brought to you for free and open access by the U.S. Department of Agriculture: Agricultural Research Service, Lincoln, Nebraska at DigitalCommons@University of Nebraska - Lincoln. It has been accepted for inclusion in Publications from USDA-ARS / UNL Faculty by an authorized administrator of DigitalCommons@University of Nebraska - Lincoln. 


\title{
Improvements in Channel Catfish Growth after Two Generations of Selection and Comparison of Performance Traits among Channel Catfish, Blue Catfish, and Hybrid Catfish Fingerlings in an Aquarium Rack System
}

\begin{abstract}
BRIAN C. SMALL*
U.S. Department of Agriculture, Agricultural Research Service, Catfish Genetics Research Unit, Thad Cochran National Warmwater Aquaculture Center, Post Office Box 38, Stoneville, Mississippi 38776, USA

Abstract.-A 9-week growth study was conducted to compare the fingerling performance of two genetic groups of channel catfish Ictalurus punctatus (U.S. Department of Agriculture [USDA] 103 and USDA303) with that of blue catfish $I$. furcatus and their hybrid in an aquarium rack system. Fish of approximately $20 \mathrm{~g}$ were randomly selected from multifamily populations and acclimated to the aquarium rack system for 2 weeks prior to the start of the 9-week study. Differences in growth indices, feed and protein efficiency, nitrogen retention, whole-body proximate composition, and plasma cortisol levels were determined at the completion of the study. The USDA303 channel catfish gained significantly more weight and consumed more feed than each of the other genetic groups. Feed and protein efficiency were similar among USDA103, USDA303, and hybrid catfish but were lower for blue catfish. Nitrogen retention was highest for hybrid catfish and lowest for blue catfish. No differences in final body composition were observed between genetic groups when final weight was used as a covariate. Plasma cortisol levels after 9 weeks ranged from $9.7 \mathrm{ng} / \mathrm{mL}$ in blue catfish to $24.5 \mathrm{ng} / \mathrm{mL}$ in USDA103 channel catfish but were not significantly different among genetic groups. This study demonstrates improved growth of the USDA303 channel catfish after two generations of selection for increased body weight and reports significant differences in performance among channel catfish, blue catfish, and hybrid catfish in an aquarium rack system.
\end{abstract}

The majority of catfish grown and sold in the United States for human consumption are channel catfish Ictalurus punctatus. In the early 1990s, interest in another ictalurid, the blue catfish I. furcatus, as a potential culture species prompted several studies to compare culture characteristics of the blue catfish to those of the channel catfish (Dunham et al. 1990, 1993; Tidwell and Mims 1990). More recently, a slow economy and the threat of foreign fish imports to the profitability of U.S. catfish farming have prompted further interest in the blue catfish as well as renewed efforts in genetic improvement of channel catfish and hybridization between channel catfish and blue catfish. Several studies comparing the performance of channel catfish, blue catfish, and their hybrid in ponds have been published (Dunham et al. 1990, 1993; Tidwell and Mims 1990; Argue et al. 2003; Bosworth et al. 2004; Li et al. 2004). However, little has been published regarding the impact of genotype-environment interactions on performance evaluations. Efficient performance evaluations of large numbers of catfish strains or families require very large pond or tank facilities with good environmental control. Often, the

\footnotetext{
* Corresponding author: bsmall@ars.usda.gov.
}

Received April 7, 2005; accepted July 28, 2005 Published online December 29, 2005 constraints of space and environmental control dictate the use of aquaria for large comparative studies of juvenile performance. The choice of culture system may, however, skew the results of the comparison. In one study, Dunham et al. (1990) found that hybrid catfish grew faster than channel catfish in ponds but grew more slowly than channel catfish in cages. Dunham et al. (1990) suggested that the observed genotype-environment interaction might be caused by behavioral differences between the two genotypes, indicating that hybrids were more active and nervous in confined environments with closer contact to the culturist. Anecdotal evidence suggests that a similar genotype-environment interaction exists for channel catfish, blue catfish, and hybrid catfish reared in aquaria.

Selected for superior growth, the U.S. Department of Agriculture (USDA) 103 line of channel catfish was developed and evaluated at the USDA Agricultural Research Service (ARS) Catfish Genetics Research Unit, Stoneville, Mississippi, and was jointly released under the name National Warmwater Aquaculture Center (NWAC) 103 to commercial producers in cooperation with the Mississippi Agricultural and Forestry Experiment Station, Thad Cochran National Warmwater Aquaculture Center, Stoneville. Results of experimental trials demonstrated that USDA103 catfish 
have faster growth than the other strains of channel catfish currently being used by commercial producers (Li et al. 1998, 2001; Silverstein et al. 1999, 2000; Jackson et al. 2003; Peterson et al. 2004). Pond studies comparing growth and processing traits of USDA103 channel catfish to hybrid catfish have produced mixed results (Bosworth et al. 2004; Li et al. 2004) and suggest the presence of familial effects within the genetic groups.

Aquarium rack systems, such as those used to rear zebrafish Danio rerio and African clawed frogs Xenopus laevis, provide a means for maintaining large numbers of juvenile fish in a very small footprint. The utilization of such systems in a breeding program could greatly expand the capacity for conducting performance comparisons of a large number of genetic groups. Another benefit of aquarium rack systems is the incorporation of onboard, integrated filtration systems for mechanical, chemical, and biological filtration, providing for water reuse and a reduction in facility water output. The purpose of this study was to assess the response of two generations of selection for increased body weight in channel catfish and compare fingerling performance of channel catfish, blue catfish, and hybrid catfish in an aquarium rack system.

\section{Methods}

Animals.-Four genetic groups of ictalurid catfish were compared for growth performance in an aquarium rack system. Channel catfish of the USDA103 line were developed as described by Wolters et al. (2000) and were further selected for rapid growth for two generations to produce the USDA303 line. The blue catfish were of the D \& B line (Dunham and Smitherman 1984), and the hybrid catfish were the $F_{1}$ offspring of pairings between USDA103 channel catfish females and males of randomly bred D \& B blue catfish. All fish used in the study were spawned at the USDA-ARS Catfish Genetics Research Unit and were reared in indoor tanks in a common environment (water temperature $=26^{\circ} \mathrm{C}, \mathrm{pH}=8.6$, and dissolved oxygen $[\mathrm{DO}]>5.0 \mathrm{mg} / \mathrm{L}$ ) under common management and feeding conditions prior to stocking into the aquarium rack system. Catfish from each genetic group were of the same year-class and of similar average weight at the start of the growth study.

Aquarium rack system.-The aquarium rack system used was a model $\mathrm{XR}_{3}$ open-rack system (Marine Biotech, Inc., Beverly, Massachusetts). The $\mathrm{XR}_{3}$ rack dimensions were $185.4 \times 40.6 \times 233.7 \mathrm{~cm}$, and the system was configured with sixteen $23-\mathrm{L}$, clear polycarbonate tanks (Figure 1). Each tank had a polycarbonate cover with access holes for feeding and water and air inlets, individual water and air feed valves, individual air stones, and rear-side, mid-tank drains with removable mesh screens to prevent feed loss. Each tank was independently fed and drained of water at a constant rate of $9.5 \mathrm{~L} / \mathrm{min}$ via an adjustable flow regulator. Three-stage particulate filtration was used, including a $150-\mu \mathrm{m}$ reusable polyester filter pad, a mechanical pleated cartridge filter, and chemical filtration via activated carbon. Biofiltration was accomplished by passing the entire volume of water through a submerged silica gravel bed in the reservoir tank. Ultraviolet (UV) sterilization designed to deliver $100,000 \mu \mathrm{W} \cdot \mathrm{s}^{-1} \cdot \mathrm{cm}^{-2}$ of UV radiation and a $1,000-\mathrm{W}$ titanium heater with a digital controller completed the system.

Experimental design.-The study was conducted in a double-blind format and in accordance with the principles and procedures approved by the Institutional Animal Care and Use Committee of the USDA-ARS Catfish Genetics Research Unit. Twice weekly, water quality tests for ammonia, nitrite, and nitrate were conducted by use of a computer-analyzed color system (Marine Enterprises International, Inc., Baltimore, Maryland), and DO was measured by use of a model 58 DO meter (YSI, Inc., Yellow Springs, Ohio). Ammonia, nitrite, and nitrate were maintained below $0.025,0.1$, and $10 \mathrm{mg} / \mathrm{L}$, respectively, and DO levels were maintained above $6 \mathrm{mg} / \mathrm{L}$.

Two weeks prior to initiation of the experiment, catfish fingerlings from each genetic group (mean weight $\pm \mathrm{SE}=20.0 \pm 3.2 \mathrm{~g}$ ) were randomly stocked into 12 aquaria. Each aquarium was stocked with 10 fish, and each genetic group was replicated in three aquaria. During the 2-week acclimation period, all fish were fed a $36 \%$ protein floating catfish feed (Farmland Industries, Inc., Kansas City, Missouri) once daily to apparent satiation. Apparent satiation was achieved by offering small quantities of feed to the fish by hand until feeding activity stopped. During the growth trial, feeding was increased to twice daily to apparent satiation, and the weight of feed consumed was recorded daily.

At the start of the growth study, two fish from each aquarium were removed and euthanatized by overdose in a solution of $300 \mathrm{mg}$ tricaine methanesulfonate (MS222; Argent Chemical Laboratories, Redmond, Washington) per liter of water, and carcasses were stored at $-20^{\circ} \mathrm{C}$ for subsequent proximate analyses. The remaining eight fish in each aquarium were anesthetized in a $100-\mathrm{mg} / \mathrm{L}$ solution of $\mathrm{MS}-222$, weighed, and measured for length. The growth trial was terminated at 9 weeks, and the remaining eight fish per aquarium were euthanatized, weighed, measured, bled, and stored at $-20^{\circ} \mathrm{C}$ for subsequent proximate analyses. 


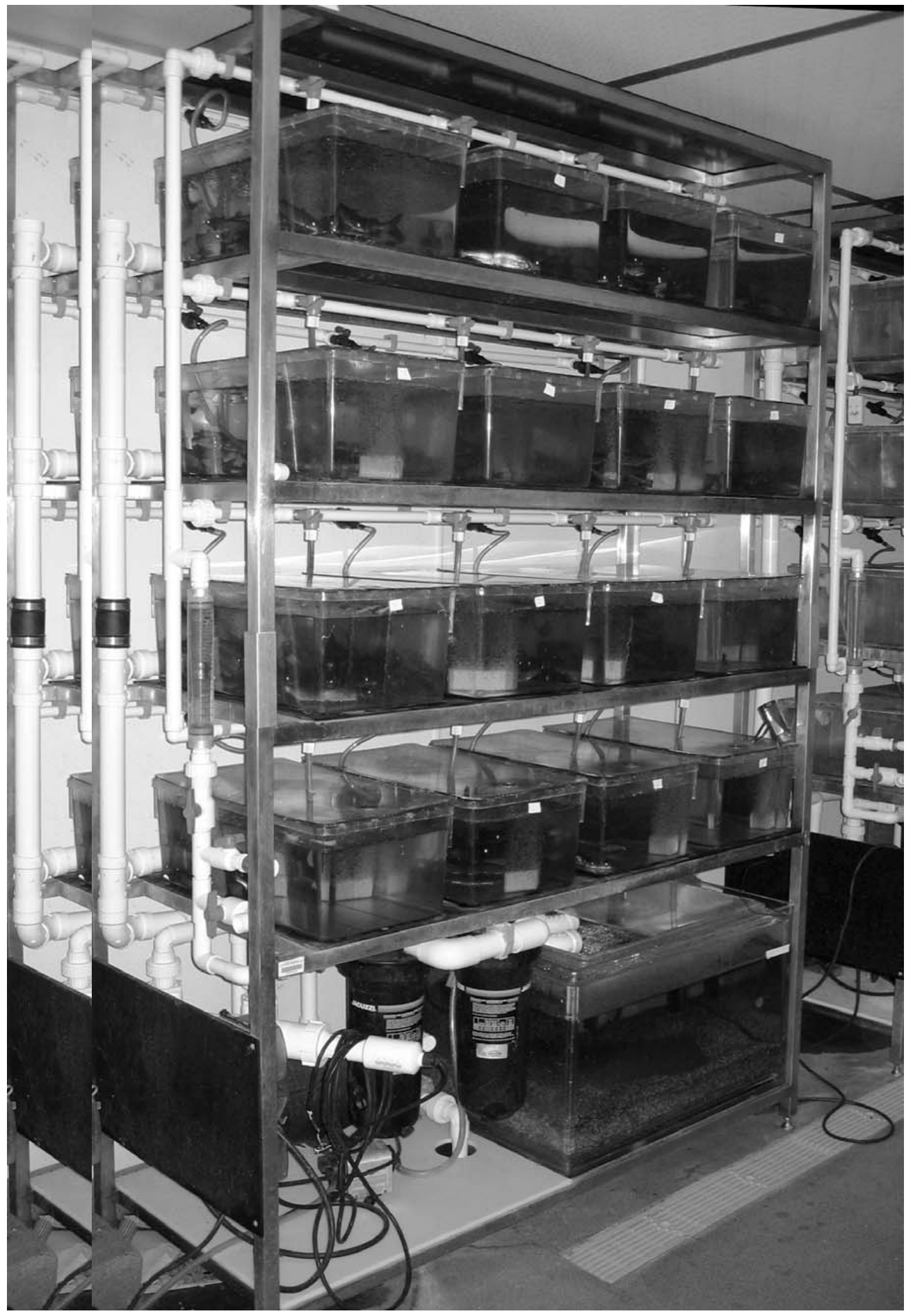

FIGURE 1.-Photograph of a modified $\mathrm{XR}_{3}$ aquarium rack system (Marine Biotech, Inc., Beverly, Massachusetts) used to compare fingerling performance of channel catfish, blue catfish, and blue catfish $\times$ channel catfish hybrids. 
Blood was collected from the caudal vasculature by use of heparinized syringes; plasma was collected by centrifugation and was then stored at $-20^{\circ} \mathrm{C}$ for subsequent cortisol analysis. Plasma cortisol was determined by a time-resolved fluoroimmunoassay that has been validated for channel catfish (Small and Davis 2002). At the end of the study, condition factor ( $K=$ $100 \times$ final weight/[length $\left.\left.{ }^{3}\right]\right)$, feed intake $(\mathrm{FI}=$ total feed consumed per tank/number of fish per tank), feed conversion ratio $(\mathrm{FCR}=100 \times$ feed consumed/weight gained), protein efficiency ratio $(\mathrm{PER}=100 \times$ protein consumed/weight gained), and nitrogen retention (NR $=100 \times$ nitrogen retained/nitrogen consumed) were calculated. Proximate analysis was conducted in duplicate on individual carcass and diet samples. Crude protein (combustion method), crude fat (ether extract), and ash (muffle furnace) contents of homogenized diet and carcass samples were determined with the methods described by the Association of Official Analytical Chemists (AOAC 1995).

Statistical analyses were conducted using the mixed procedure of the Statistical Analysis System (SAS Institute). Data on weight, length, $K$, FI, FCR, PER, $\mathrm{NR}$, and plasma cortisol were subjected to one-way analyses of variance (ANOVAs) that employed genetic group as a fixed effect and aquarium within genetic group as a random effect. Body composition indices were subjected to one-way ANOVAs containing genetic group as the fixed effect, final weight as a covariate, and aquarium within genetic group as a random effect. For all analyses, aquarium was the experimental unit and the mean square of aquarium within genetic group was used as the error term in tests of differences among genetic group means. Differences among fixed effects were considered significant at $P$ values less than 0.05 .

\section{Results}

Body weight and length gain were significantly higher for both genetic groups of channel catfish after only 3 weeks than for blue catfish and hybrid catfish (Figure 2). Higher weights and lengths for channel catfish were also observed at 6 and 9 weeks, but by 6 weeks the USDA303 channel catfish had the highest weights of all the genetic groups. There were no differences in length between the two channel catfish lines. The differences in weight-to-length ratios were reflected in the $K$-values of these two genetic groups (Table 1). Large differences in FI were also observed among all four genetic groups, and FI was positively correlated to weight gain $(P=0.0004 ; r=0.999)$. The hybrid catfish had a mean FCR similar to those of both channel catfish groups, while blue catfish demonstrated a poorer FCR. Channel catfish and hybrid catfish were also similar in their efficiency of converting dietary protein into weight gain, as indicated by their PERs. Blue catfish, however, had a lower average PER. Actual retention of nitrogen from consumed protein was highest for the hybrid catfish, intermediate for channel catfish, and lowest for blue catfish. Basal plasma cortisol levels at the end of the 9-week growth study were not significantly different among the genetic groups and were not correlated to weight gain $(P=0.2162)$ or FI $(P=0.2254)$. Body composition indices for the four genetic groups indicated a tendency toward lower protein and ash contents and higher fat content for the USDA103 and USDA303 channel catfish at the end of the study; however, when final weight was used as a covariate in the statistical analysis, mean body composition indices were not significantly different among the genetic groups (Table 2).

\section{Discussion}

Two generations of selection for increased body weight in channel catfish resulted in a $21 \%$ increase in USDA303 channel catfish body weight relative to that of randomly bred USDA103 channel catfish at the end of the 9-week growth study. Relative weight differences between these two genetic groups were established by the time the fish reached approximately $80 \mathrm{~g}$ (6 weeks in the present study), at which time the average weight of USDA303 channel catfish was 23\% higher than that of USDA103 channel catfish. Dunham and Brummett (1999) also found that size differences between channel catfish selected over two generations for increased body weight were first significant when the fish reached approximately $80 \mathrm{~g}$. Dunham and Brummett (1999) reported a $12 \%$ increase in Kansas select channel catfish body weight at $80 \mathrm{~g}$ and at market size relative to randomly bred Kansas channel catfish. Together, these results suggest that the improved growth of the USDA303 channel catfish might also be observed at market size. Research is ongoing to determine the effect of two generations of selection on the time required to reach market size and processing traits.

Comparison of performance traits among the four genetic groups in the aquarium rack system clearly demonstrated the superiority of the USDA303 line of channel catfish. A high correlation between weight and FI suggests that FI was the limiting factor for all four genetic groups in the present study. Low FI and the poor FCR of blue catfish contributed to poor values for growth, $K$, PER, and NR. Although hybrid catfish consumed less and grew more slowly than the two channel catfish lines, the hybrids were as efficient as the channel catfish in converting feed and dietary 

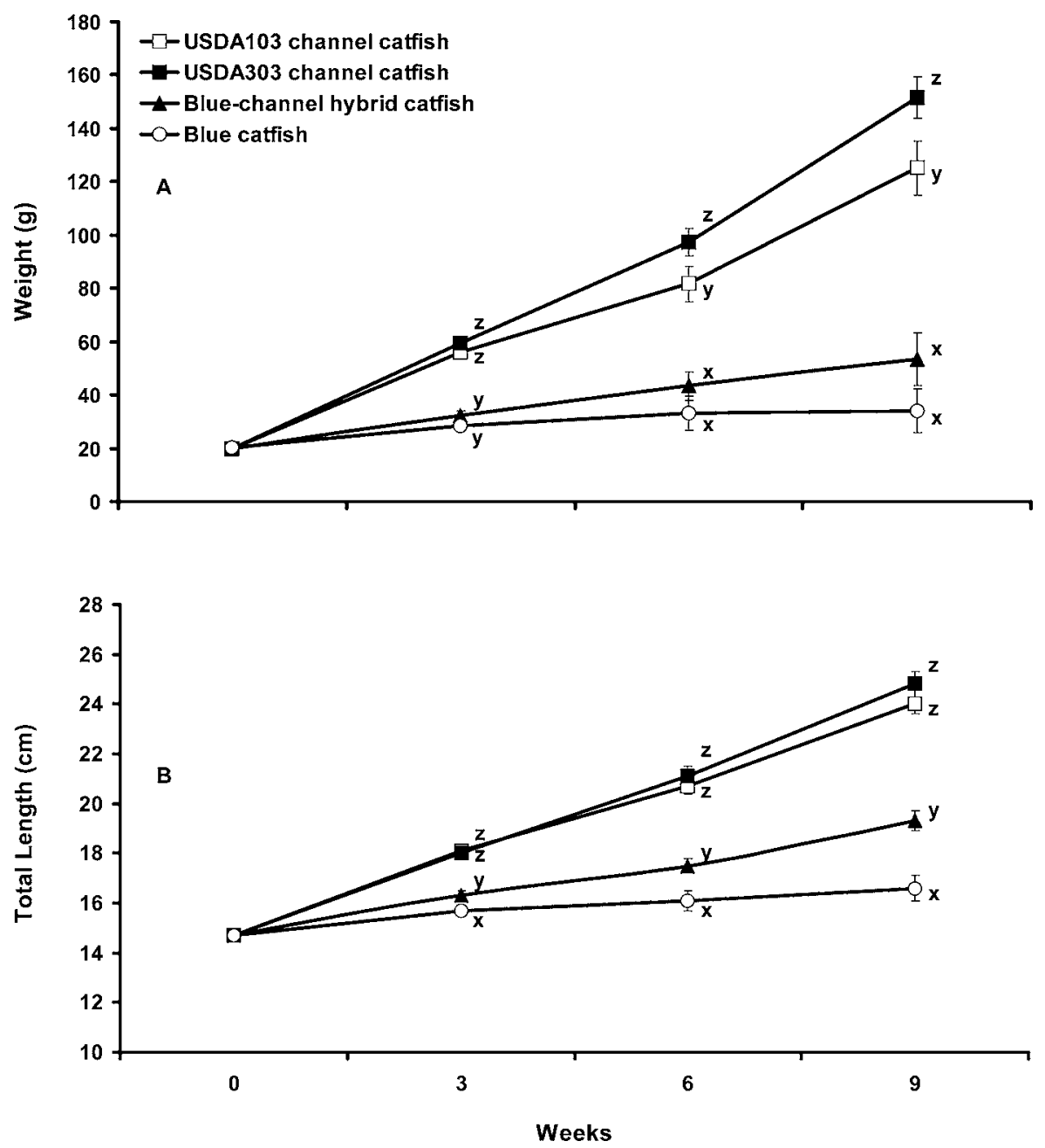

FIGURE 2.-Cumulative mean (A) weight and (B) length of USDA103 and USDA303 channel catfish, blue catfish, and blue catfish $\times$ channel catfish hybrids reared in an aquarium rack system for 9 weeks. Significant differences $(P<0.05)$ within a time period between genetic group means $( \pm \mathrm{SE})$ are indicated by different letters.

protein to weight gain. Coupled with a higher level of NR, these data suggest that hybrid catfish more efficiently convert dietary protein to body protein than do channel catfish; such findings might explain reports of higher carcass and fillet yields of hybrid catfish relative to channel catfish (Argue et al. 2003; Bosworth et al. 2004). With regard to weight and FI comparisons, some studies have demonstrated that hybrid catfish outperform channel catfish when reared in ponds (Dunham et al. 1990; Li et al. 2004), and others have reported just the opposite (Bosworth et al. 2004). Reports of growth comparisons between blue catfish and channel catfish are also inconsistent (Dunham et al. 1993). These inconsistencies among reported growth comparisons of ictalurids may be the result of many variables, including parental stocks, environment, feeding regimes, and stocking density. Even so, the degree of poor performance observed for blue catfish and hybrid catfish in the present experiment is generally contrary to the results of studies conducted in ponds, suggesting a potential genotype-rearing environment interaction.

Earlier reports have suggested that blue catfish do not tolerate handling or environmental stress as well as channel catfish do (Dunham et al. 1993). As a result, poor performance of blue catfish in high-density culture systems is often blamed on stress. In teleost fish, cortisol is accepted as the primary stress hormone. Measurements of plasma cortisol concentrations are convenient and perhaps the most common measure of 
TABLE 1.-Least-squares means for final condition factor $(K)$, feed intake (FI), feed conversion ratio (FCR), protein efficiency ratio (PER), nitrogen retention (NR), and plasma cortisol concentration of channel catfish, blue catfish, and hybrid blue $\times$ channel catfish reared in an aquarium rack system for 9 weeks. Within rows, means followed by different letters are significantly different $(P<0.05)$.

\begin{tabular}{lrrrrrr}
\hline & \multicolumn{2}{c}{ Channel catfish } & & & & \\
\cline { 2 - 3 } Variable & USDA103 & USDA303 & Hybrid catfish & Blue catfish & SE \\
\hline$K^{\mathrm{a}}$ & $1.32 \mathrm{y}$ & $1.48 \mathrm{z}$ & $1.00 \mathrm{x}$ & $0.77 \mathrm{w}$ & 0.05 \\
$\mathrm{FI}^{\mathrm{b}}$ & $130.4 \mathrm{y}$ & $166.7 \mathrm{z}$ & $38.1 \mathrm{x}$ & $18.0 \mathrm{w}$ & 6.5 \\
$\mathrm{FCR}^{\mathrm{c}}$ & $1.22 \mathrm{z}$ & $1.24 \mathrm{z}$ & $1.22 \mathrm{z}$ & $1.62 \mathrm{y}$ & 0.04 \\
PER $^{\mathrm{d}}$ & $2.32 \mathrm{z}$ & $2.20 \mathrm{z}$ & $2.25 \mathrm{z}$ & $1.68 \mathrm{y}$ & 0.06 \\
$\mathrm{NR}^{\mathrm{e}}$ & $36.7 \mathrm{y}$ & $36.3 \mathrm{y}$ & $42.0 \mathrm{z}$ & $33.0 \mathrm{x}$ & 1.1 \\
Cortisol $(\mathrm{ng} / \mathrm{mL})$ & 24.5 & 17.4 & 13.0 & 9.7 & 3.4 \\
\hline
\end{tabular}

${ }^{\mathrm{a}} K=100 \times$ final weight $(\mathrm{g}) /[$ length $(\mathrm{cm})]$.

${ }^{\mathrm{b}} \mathrm{FI}=$ total feed consumed per tank $(\mathrm{g}) /$ number of fish per tank.

${ }^{\mathrm{c}} \mathrm{FCR}=$ feed consumed $(\mathrm{g}) /$ weight gained $(\mathrm{g})$.

${ }^{\mathrm{d}} \mathrm{PER}=100 \times$ protein consumed $(\mathrm{g}) /$ weight gained $(\mathrm{g})$.

${ }^{\mathrm{e}} \mathrm{NR}=100 \times$ retained nitrogen $(\mathrm{g}) /$ nitrogen consumed $(\mathrm{g})$.

fish stress reported in the literature. Fish rearing conditions such as water quality, handling, and stocking density are known to have significant effects on the plasma cortisol concentration in catfish (Tomasso et al. 1981a, 1981b; Patiño et al. 1986; Small 2004). Several studies have also demonstrated negative effects of handling, crowding, social, and behavioral stressors on fish health and immune function (Ellis 1981; Barton and Iwama 1991; Schreck 1996; Wendelaar Bonga 1997). In general, prolonged elevations of plasma cortisol levels associated with chronic stress are considered to be detrimental to fish performance and health. However, plasma cortisol levels of both blue catfish and hybrid catfish were low in the present study, suggesting that these two genetic groups were not chronically stressed in the classical sense during rearing in the aquarium rack system environment. Furthermore, average circulating cortisol levels of the two channel catfish lines tended to be higher than those of the blue catfish and hybrid catfish. Although these results appear to rule out chronic stress as the cause for poorer growth performance among blue catfish and hybrid catfish relative to channel catfish reared in the aquarium rack system, the potential for alternative stress coping styles affecting energy balance and growth should not be ruled out and deserves further investigation (Van Weerd and Komen 1998).

In conclusion, this study demonstrates improved growth of the USDA303 channel catfish after two generations of selection for increased body weight and reports significant differences in performance among channel catfish, blue catfish, and hybrid catfish in an aquarium rack system. Although genetics alone may have contributed to the observed differences between channel catfish, blue catfish, and hybrid catfish, the degree of poor performance observed for blue catfish and hybrid catfish is generally contrary to the results of studies conducted in ponds and suggests a potential genotype-rearing environment interaction. However, no correlation could be made between plasma cortisol concentrations (indicative of stress) and growth performance. The aquarium rack system was found to be an efficient and effective culture system for rearing catfish fingerlings, but potential genotype-environment interactions should be considered when comparing performance traits of different genetic groups.

\section{Acknowledgments}

I thank Kira Johnson and Jimmie Warren for their technical assistance during this study. Mention of trade names, proprietary products, or specific equipment

TABLE 2.-Least-squares means ( \pm SE) for body composition indices (dry-weight basis) of channel catfish, blue catfish, and blue $\times$ channel catfish hybrids reared in an aquarium rack system for 9 weeks. Within rows, means are not significantly different $(P<0.05)$

\begin{tabular}{|c|c|c|c|c|}
\hline \multirow[b]{2}{*}{ Variable } & \multicolumn{2}{|c|}{ Channel catfish } & \multirow[b]{2}{*}{ Hybrid catfish } & \multirow[b]{2}{*}{ Blue catfish } \\
\hline & USDA103 & USDA303 & & \\
\hline Protein (\%) & $53.9 \pm 1.5$ & $51.2 \pm 2.4$ & $63.0 \pm 1.6$ & $63.2 \pm 2.3$ \\
\hline Fat $(\%)$ & $34.2 \pm 1.3$ & $37.2 \pm 2.1$ & $26.1 \pm 1.4$ & $24.6 \pm 2.0$ \\
\hline Ash & $11.1 \pm 0.6$ & $10.3 \pm 0.9$ & $12.6 \pm 0.6$ & $12.2 \pm 0.9$ \\
\hline
\end{tabular}


does not constitute a guarantee or warranty by the USDA and does not imply approval to the exclusion of other products that may be suitable.

\section{References}

AOAC (Association of Official Analytical Chemists). 1995. Official methods of analysis of AOAC International, 16th edition. AOAC International, Arlington, Virginia.

Argue, B. J., Z. Liu, and R. A. Dunham. 2003. Dress-out and fillet yields of channel catfish, Ictalurus punctatus, blue catfish, Ictalurus furcatus, and their $\mathrm{F}_{1}, \mathrm{~F}_{2}$, and backcross hybrids. Aquaculture 228:81-90.

Barton, B. A., and G. K. Iwama. 1991. Physiological changes in fish from stress in aquaculture with emphasis on the response and effects of corticosteroids. Annual Review of Fish Diseases 1:3-26.

Bosworth, B. G., W. R. Wolters, J. L. Silva, R. S. Chamul, and S. Park. 2004. Comparison of production, meat yield, and meat quality traits of NWAC103 line channel catfish, Norris line channel catfish, and female channel catfish $\times$ male blue catfish $\mathrm{F}_{1}$ hybrids. North American Journal of Aquaculture 66:177-183.

Dunham, R. A., and R. E. Brummett. 1999. Response of two generations of selection to increased body weight in channel catfish, Ictalurus punctatus, compared to hybridization with blue catfish, I. furcatus, males. Journal of Applied Aquaculture 9(3):37-45.

Dunham, R. A., R. E. Brummett, M. O. Ella, and R. Oneal Smitherman. 1990. Genotype-environment interactions for growth of blue, channel, and hybrid catfish in ponds and cages at varying densities. Aquaculture 85:143-151.

Dunham, R. A., C. Hyde, M. Masser, J. A. Plumb, R. Oneal Smitherman, and A. C. Ramboux. 1993. Comparison of channel catfish, Ictalurus punctatus, and blue catfish, I. furcatus. Journal of Applied Aquaculture 3(3-4):257267.

Dunham, R. A., and R. O. Smitherman. 1984. Ancestry and breeding of catfish in the United States. Alabama Agriculture Experiment Station, Auburn University, Alabama.

Ellis, A. E. 1981. Stress and modulation of defense mechanisms in fish. Pages 147-169 in A. D. Pickering, editor. Stress in fish. Academic Press, London.

Jackson, L. S., E. H. Robinson, M. H. Li, W. R. Wolters, and D. A. McKee. 2003. Restricted and satiate feeding of two genetically isolated strains of juvenile channel catfish Ictalurus punctatus reared on $28 \%$ and $32 \%$ protein diets. Journal of the World Aquaculture Society 34:478-486.

Li, M. H., E. H. Robinson, and W. R. Wolters. 1998. Evaluation of three strains of channel catfish Ictalurus punctatus fed three concentrations of protein and digestible energy. Journal of the World Aquaculture Society 29:155-168.

Li, M. H., E. H. Robinson, B. B. Manning, B. G. Bosworth, and W. R. Wolters. 2001. Comparison of growth, processing yield, and body composition of USDA103 and Mississippi "normal" strains of channel catfish Ictalurus punctatus fed diets containing three concentrations of protein. Journal of the World Aquaculture Society 32:402-408.

Li, M. H., E. H. Robinson, B. B. Manning, D. R. Yant, N.
Chatakondi, B. G. Bosworth, and W. R. Wolters. 2004. Comparison of channel catfish, Ictalurus punctatus, and the channel $\times$ blue catfish, $I$. punctatus $\times I$. furcatus, $\mathrm{F}_{1}$ hybrid for growth, feed efficiency, processing yield, and body composition. Journal of Applied Aquaculture 15(34):63-71.

Patiño, R., C. B. Schreck, J. L. Banks, and W. S. Zaugg. 1986. Effects of rearing conditions on the developmental physiology of smolting coho salmon. Transactions of the American Fisheries Society 115:828-837.

Peterson, B. C., B. C. Small, and B. Bosworth. 2004. Effects of bovine growth hormone (Posilac) on growth performance, body composition, and IGFBPs in two strains of channel catfish. Aquaculture 232:651-663.

SAS Institute. 1996. SAS/STAT software: changes and enhancements through release 6.11. SAS Institue, Cary, North Carolina.

Schreck, C. B. 1996. Immunomodulation: endogenous factors. Pages 311-337 in G. Iwama and T. Nakanishi, editors. The fish immune system: organism, pathogen, and environment. Academic Press, London.

Silverstein, J. T., W. R. Wolters, and M. Holland. 1999. Evidence of differences in growth and food intake regulation in different genetic strains of channel catfish. Journal of Fish Biology 54:607-615.

Silverstein, J. T., W. R. Wolters, M. Shimizu, and W. W. Dickhoff. 2000. Bovine growth hormone treatment of channel catfish: strain and temperature effects on growth, plasma IGF-I levels, feed intake, and efficiency and body composition. Aquaculture 190:77-88.

Small, B. C. 2004. Effect of isoeugenol sedation on plasma cortisol, glucose, and lactate dynamics in channel catfish Ictalurus punctatus exposed to three stressors. Aquaculture 238:469-481.

Small, B. C., and K. B. Davis. 2002. Validation of a timeresolved fluoroimmunoassay for measuring plasma cortisol in channel catfish Ictalurus punctatus. Journal of the World Aquaculture Society 33:184-187.

Tidwell, J. H., and S. D. Mims. 1990. A comparison of second-year growth of blue catfish and channel catfish in Kentucky. Progressive Fish-Culturist 52:203-204.

Tomasso, J. R., K. B. Davis, and N. C. Parker. 1981a. Plasma corticosteroid dynamics in channel catfish, Ictalurus punctatus (Rafinesque), during and after oxygen depletion. Journal of Fish Biology 18:519-526.

Tomasso, J. R., K. B. Davis, and B. A. Simco. 1981b. Plasma corticosteroid dynamics in channel catfish (Ictalurus punctatus) exposed to ammonia and nitrite. Canadian Journal of Fisheries and Aquatic Sciences 38:1106-1112.

Van Weerd, J. H., and J. Komen. 1998. The effects of chronic stress on growth in fish: a critical appraisal. Comparative Biochemistry and Physiology 120A:107-112.

Wendelaar Bonga, S. E. 1997. The stress response in fish. Physiological Reviews 77:591-625.

Wolters, W. R., G. C. Waldbieser, B. G. Bosworth, J. T. Silverstein, E. H. Robinson, M. Li, D. J. Wise, D. Freeman, P. Klesius, and K. B. Davis. 2000. Notice of joint release of catfish line USDA103, which has improved growth performance. U.S. Department of Agriculture, Agricultural Research Service, Washington, D.C., and Mississippi Agricultural and Forestry Experiment Station, Mississippi State, Mississippi. 